\title{
The 2017 ABJS Nicolas Andry Award: Advancing Personalized Medicine for Clubfoot Through Translational Research
}

\author{
Matthew B. Dobbs MD, Christina A. Gurnett MD, PhD
}

Received: 9 September 2016/Accepted: 16 February 2017/Published online: 24 February 2017

(C) The Association of Bone and Joint Surgeons \& 2017

\begin{abstract}
Background Clubfoot is one of the most common pediatric orthopaedic disorders. While the Ponseti method has revolutionized clubfoot treatment, it is not effective for all patients. When the Ponseti method does not correct the foot, patients are at risk for lifelong disability and may require more-extensive surgery.

Questions/Purposes (1) What genetic and morphologic abnormalities contribute to the development of clubfoot? (2) How can this information be used to devise personalized treatment paradigms for patients with clubfoot?

Methods Human gene sequencing, molecular genetic engineering of mouse models of clubfoot, MRI of clubfoot, and development of new treatment methods all have been used by our group to understand the biological basis and improve therapy for this group of disorders.
\end{abstract}

\footnotetext{
One or more authors certifies that he (MBD), or a member of her immediate family (CAG) has received or may receive payments or benefits, during the study period, an amount of USD 10,000 to USD 100,000 from D-Bar Enterprises (St Louis, MO, USA).

The institution of one or more of the authors (MBD and CAG) has received, during the study period, funding from Shriners Hospital for Children (St Louis, MO, USA).

All ICMJE Conflict of Interest Forms for authors and Clinical Orthopaedics and Related Research ${ }^{\circledR}$ editors and board members are on file with the publication and can be viewed on request.

This work was performed at Washington University School of Medicine and Shriners Hospital (St Louis, MO, USA).
}

\section{B. Dobbs ( $\square)$}

Department of Orthopaedics, St. Louis Children's Hospital, 1 Children's Place, Suite 4S-60, St. Louis, MO 63110, USA

e-mail: dobbsm@wudosis.wustl.edu; MDobbs@clinorthop.org

\section{A. Gurnett}

Department of Neurology, Washington University School of Medicine in St Louis, St. Louis, MO, USA
Results We gained new insight into clubfoot pathogenesis from our discovery that mutations in the PITX1-TBX4HOXC transcriptional pathway cause familial clubfoot and vertical talus in a small number of families, with the unique lower limb expression of these genes providing an explanation for the lack of upper extremity involvement in these disorders. MRI studies revealed corresponding morphologic abnormalities, including hypomorphic muscle, bone, and vasculature, that are not only associated with these gene mutations, but also are biomarkers for treatment-resistant clubfoot.

Conclusions Based on an understanding of the underlying biology, we improved treatment methods for neglected and syndromic clubfoot, developed new treatment for congenital vertical talus based on the principles of the Ponseti method, and designed a new dynamic clubfoot brace to improve strength and compliance.

\section{Introduction}

Clubfoot is one of the most common pediatric orthopaedic disorders. While the Ponseti method has revolutionized clubfoot treatment and typically results in excellent correction and long-term results, it is not effective for all patients. Clubfeet that are recalcitrant to treatment with the Ponseti method often ultimately undergo more-extensive surgery, exposing them to increased risk of complications. Some of these patients experience lifelong disability. To improve the lives of all children with clubfoot, we believe it is critical not only to understand the genetic and morphologic abnormalities contributing to foot development, but also to use this information to devise personalized treatment paradigms. Our work leverages scientific advances of the past decades, including human gene sequencing, molecular genetic engineering of mouse 
models, MRI, and novel treatment technologies. New insight into clubfoot pathogenesis arose from our identification of mutations in the PITX1-TBX4-HOXC transcriptional pathway in several families with clubfoot and vertical talus, although these genetic abnormalities overall are rare. MRI studies subsequently showed that hypomorphic muscle, bone, and vasculature, are not only associated with these developmental gene mutations, but also are biomarkers for treatment-resistant clubfoot. Based on an understanding of the underlying biology, we modified brace design to improve patient tolerance, developed a new treatment for congenital vertical talus, and are improving treatment methods for neglected and syndromic clubfoot. Knowledge of the genetic and biological factors responsible for treatment-resistant clubfoot will finally allow clinicians to develop more successful personalized therapies.

\section{Background}

Isolated clubfoot, also called talipes equinovarus, is a common, but serious congenital birth defect with an estimated birth prevalence of one per 1000 live births [74]. Recognizable at birth, the rigidness of a clubfoot makes it distinguishable from positional foot anomalies. Clubfoot is not passively correctable; left untreated, as commonly occurs in many parts of the world, clubfoot can result in infections, foot and leg deformities, pain that greatly limits mobility, and social stigma and economic hardship.

Historically, clubfoot treatment has been based on different methods of manipulating and immobilizing the foot, while others focused on more-invasive surgical options. Unfortunately, none produced predictable or satisfying results. Many of the manipulative methods resulted in patients still needing extensive soft tissue release surgery. Dr. Ignacio Ponseti noted the pain and stiffness in surgically treated feet as they matured, prompting him to study the anatomy of the clubfoot and develop a gentle manipulative technique that produced excellent correction without the scarring and stiffness seen with surgery. The Ponseti method of clubfoot treatment [59], first described in 1963 [60], consists of weekly manipulation and serial casting starting ideally within the first month of life, culminating with a percutaneous tenoachilles tenotomy performed in the office, followed by a final cast and prolonged use of a foot abduction brace for at least 4 years. During the ensuing 40 years, his method gradually replaced the once commonplace extensive soft tissue surgery for treatment and transformed a stiff clubfoot (Fig. 1A) into an anterograde flexible foot (Fig. 1B).

Although feet treated with the Ponseti method had excellent short-term correction and long-term pain-free and functional feet [45], we were the first to formally demonstrate their superior long-term outcome compared with feet treated with extensive soft tissue release surgery [19]. Despite superior outcomes, not all patients respond well [22] to the Ponseti method, prompting us to pursue a basicscience approach to understanding the pathogenesis of this heterogeneous disorder.

Researchers have proposed many theories regarding the pathogenesis of clubfoot, including intrauterine immobility, neurologic, vascular, and connective tissue fibrosis [54]. Some reports described histologic and structural abnormalities in clubfoot, including malposition of the tarsal bones, calf muscle atrophy, short foot length, and vascular abnormalities such as absent posterior tibial artery, malposition of tendinous attachments, increased prevalence of flexor digitorum longus muscle, and hypertrophy and contracture of joint capsules and ligaments
Fig. 1A-B The photographs show (A) unilateral right-sided clubfoot in an infant before treatment and (B) residual size difference after successful treatment with the Ponseti method.
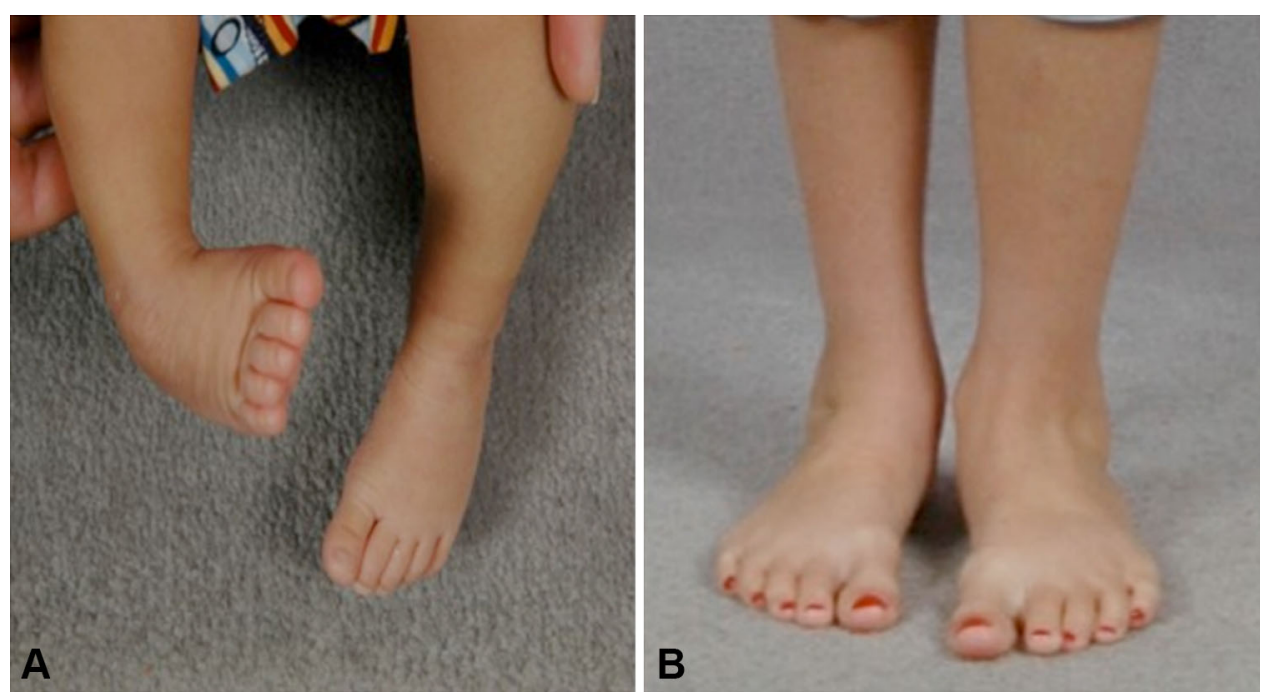
[23, 30, 42]. Based on marked thickening and shortening of tendons and ligaments in the clubfeet of fetuses aborted at 16 to 20 weeks gestation, Ippolito and Ponseti proposed "retracting fibrosis" as the primary etiologic factor in clubfoot [41]. However, uncertainty existed regarding whether many of the observed abnormalities are primary or secondary in nature.

Genetic studies represent an effective method of determining whether clubfoot is a primary abnormality of muscle, tendon, nerve, or alternatively, a developmental abnormality affecting multiple tissues. Nearly $80 \%$ of all clubfeet occur as an isolated birth defect, while others are associated with chromosomal or genetic abnormalities, or neurologic disorder, such as arthrogyryposis, myelomeningocele, or myotonic dystrophy [37]. Family history is positive for clubfoot in approximately $25 \%$ of all patients with idiopathic clubfoot [37]. A genetic basis of clubfoot also is supported by a higher concordance rate in identical compared with fraternal twins (33\% vs 3\%) [73]. However, when we started our genetic studies of clubfoot, few, if any, genes responsible for isolated clubfoot had been reported. Therefore, we sought to determine whether specific genetic factors could be identified that influenced not only the risk for clubfoot but also the morphologic features of the lower leg and their subsequent response to treatment.

\section{Summary of Research Program}

\section{Genetic Studies of Clubfoot}

\section{PITX1 Mutations and Deletions in Clubfoot}

Our genetic studies capitalize on the rapid advances in sequencing technology that have made low-cost interrogation of the human genome a reality. We identified a large five-generation family with a spectrum of lower-limb birth defects including isolated clubfoot and used positional cloning methods to discover a single missense mutation in the paired-homeodomain gene PITX1 [36]. While clubfoot was the most-common abnormality, some family members had hip dysplasia, flat foot, tibial hemimelia, or preaxial polydactyly. PITX1 is a transcription factor involved in early limb development, and is one of a handful of genes expressed preferentially in the lower limb, making it critical to leg development [48]. Interestingly, alterations of PITX1 expression are more likely to result in right-sided limb defects, suggesting that the related homeobox gene, PITX2, whose expression is known to be asymmetric in the lower limb [50], may compensate. As a major gene responsible for lower-limb development, alterations of PITX1 also are involved in several important evolutionary adaptations in vertebrates, including the loss of pelvic structures that arose as manatee returned to the water [64].

Later, we identified a genomic deletion of PITX1 in one small family during a systematic evaluation of copy number variants (small microdeletions or microduplications, also called CNVs) in 413 patients with clubfoot [4]. Interestingly, larger deletions including PITX1 and surrounding regions result in mirror-image polydactyly [43], and rearrangements of nearby regions result in Liebenberg syndrome, an autosomal dominant upper-limb malformation in which the arm acquires morphologic characteristics of a leg (homeotic-transformation) [68].

Although mouse models of clubfoot have not been reported previously despite the proliferation of knockout mice, we identified a clubfoot-like phenotype in mice missing a single copy of PITX1 [4], again suggesting a highly conserved role for this gene in lower limb development. Interestingly, not all of the PITX1 -/+ mice developed clubfoot, and some had only unilateral clubfoot, suggesting that other nongenetic effects or stochastic effects may influence the occurrence of the malformation. Micro-MRI methods were developed in collaboration with radiologists to specifically image the small clubfoot mouse limbs. Clubfoot was often unilateral in the PITX1 $-/+$ mice (Fig. 2A), and MRI evaluations of unilateral cases revealed hypoplastic peroneal arteries in the affected clubfoot limb (Fig. 2B), and hypoplasia of the peroneus muscles in the clubfoot limb (Fig. 2C). Our human studies on a patient with PITXI deletion, described below in the section on morphologic abnormalities, mirrored these findings.

PITX1 mutations are associated with a high rate of additional musculoskeletal comorbidities, including hip dysplasia and tibial hemimelia. However, mutations in PITX1 have been found in only a handful of patients and are a relatively rare cause of isolated clubfoot.

\section{Chromosome 17q23 Duplications Containing TBX4}

Our genomic analysis of patients with clubfoot also revealed recurrent $\mathrm{CNVs}$ of chromosome $17 \mathrm{q} 23$. This region contains the T-box transcription factor $T B X 4$ [3], which is an important factor in lower limb development and a downstream transcriptional target of the homeodomain gene PITX1 [48, 52]. Chromosome 17q23 CNVs were present in more than $5 \%$ of all familial patients with clubfoot, making this the most common cause of isolated clubfoot identified to date [2]. Missense mutations in $T B X 4$, a T-box transcription factor important in lower limb development, were previously associated with small patella syndrome [10]. While most patients that we and others identified with chromosome $17 \mathrm{q} 23$ microduplications have 

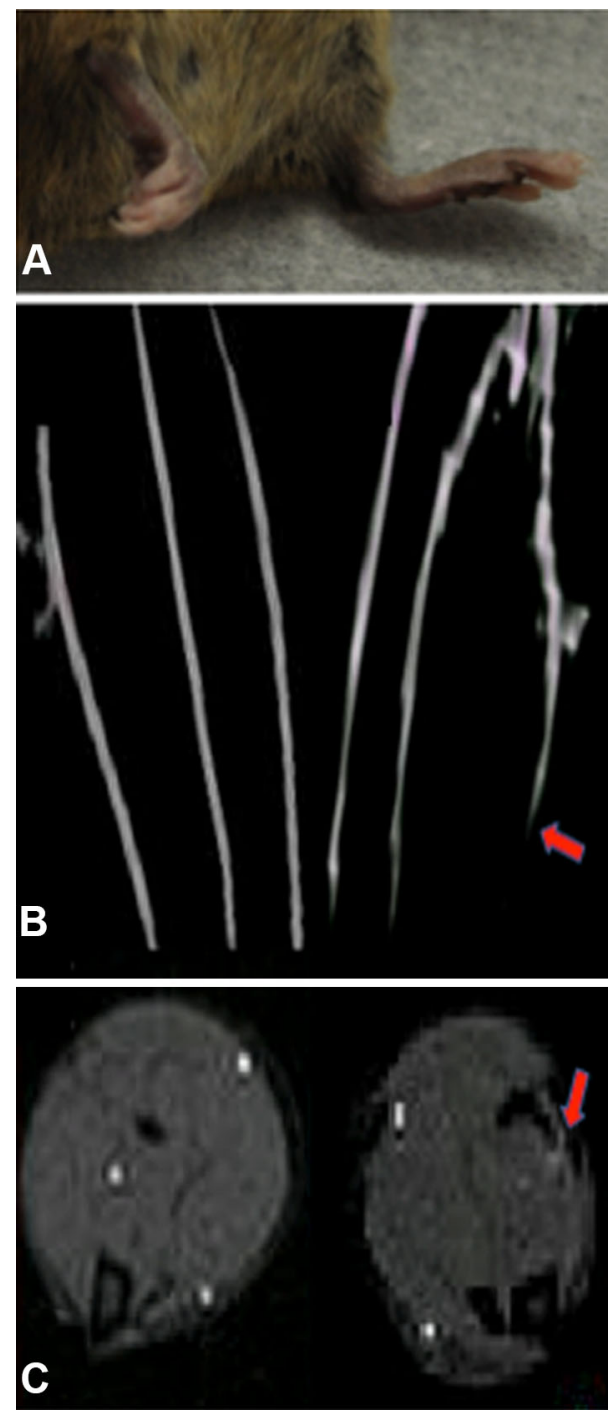

Fig. 2A-C MR images of clubfoot deformity in the PITX1-/+ mouse show (A) right clubfoot (left in image) and normal left foot (right), and (B) a normal three-vessel MR angiogram of the unaffected limb (left) and hypoplastic peroneal artery (red arrow) in the clubfoot limb (right). (C) MR image shows a normal muscle in sagittal section of the unaffected lower limb (left) and lateral muscle hypoplasia (red arrow) in the clubfoot limb (right).

isolated clubfoot [49], at least one patient had multiple congenital anomalies (congenital heart defects, microcephaly, facial dysmorphism, hearing loss) suggesting a possible greater risk for additional birth defects [58]. Chromosome 17q23 CNVs, which can be identified clinically with routine chromosomal microarray studies, are important to identify because they also often are associated with treatment-resistant clubfoot and hip dysplasia, as well as the approximately $50 \%$ recurrence risk resulting from autosomal dominant inheritance.

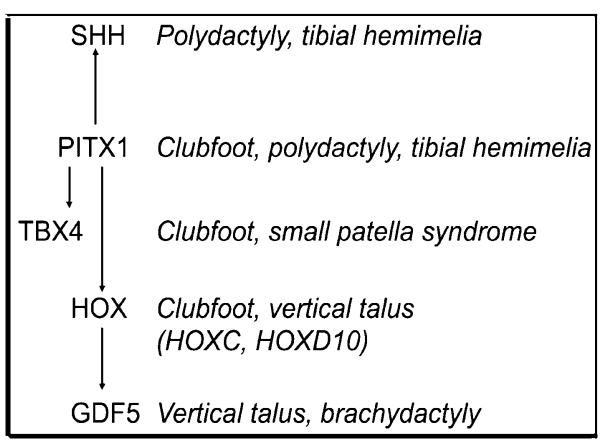

Fig. 3 This diagram illustrates the genes involved in clubfoot and vertical talus pathogenesis.

\section{HOXC Deletions}

PITX1, TBX4, and some HOXC genes are members of a very small group of genes that are preferentially expressed in the hindlimb of mice where they are essential for early hindlimb growth and specification [35, 47, 51, 57, 65, 70] (Fig. 3). In fact, there are very few other genes that are uniquely expressed in the hindlimb compared with the forelimb, therefore, it is logical that these genes are responsible for clubfoot. In our CNV screen, we also identified a $\mathrm{HOXC13}$ deletion that segregated with clubfoot in a three-generation family [3]. Deletions of part of the HOXC gene cluster were later identified by our group in two of five families with autosomal dominant isolated congenital vertical talus, suggesting that this is a common cause of familial vertical talus [5]. Interestingly, HOXD10 mutations were previously identified in two families with vertical talus [18, 66], strongly supporting a role for homeobox gene mutations in the etiology of isolated vertical talus.

\section{Genome-wide Association Study of Common Variants Associated With Clubfoot}

We tested the common disease/common variant hypothesis of disease etiology by performing a genome-wide association study of isolated clubfoot in nearly 400 patients with clubfoot followed by confirmation with an independent cohort [76]. The strongest evidence for an association of clubfoot was found with a single nucleotide polymorphism (SNP) near the transcriptional regulators NCOR2 and ZNF664. Additional clubfoot-associated SNPs were near the FOXN3, SORCS1, and MMP7/TMEM123 genes. These data suggest a role for common genetic variation near several transcriptional regulators that have not previously been implicated in clubfoot pathogenesis, although it is not yet clear how these variants influence limb development. 
However, these genetic abnormalities account for only a small amount of the heritability of clubfoot, and suggest a more important role for rare variants, such as those identified in the PITX1-TBX4-HOXC pathway. Because mutations in the PITX1-TBX4-HOXC pathway are infrequent in patients with clubfoot, other genetic mechanisms remain to be discovered.

\section{Morphologic Abnormalities Associated With Clubfoot}

Few MRI studies of clubfoot limbs were published before we began to analyze the clubfoot-like feet of our PITX1 haploinsufficient mice. Previous studies in humans include three small MRI series that showed quantitative reduction in total muscle volume of unilateral clubfoot limbs $[24,40,53]$, that was confirmed in a larger study of 20 patients [55]. Ippolito and colleagues [40] described muscular atrophy that was present in newborns before treatment and increased with age. However, it was not known whether morphologic abnormalities were indicative of specific genetic abnormalities, or whether they could be used as biomarkers of clubfoot treatment resistance.

\section{Lateral Muscle and Vascular Anomalies in Patients With PITX1-TBX4-HOXC Mutations}

Our imaging studies provided evidence that mutations in the PITX1-TBX4-HOXC pathway are associated with specific muscle hypoplasia. First, we identified lateral muscle hypoplasia in a patient with unilateral clubfoot with a PITX1 mutation and saw a remarkably similar abnormality in our PITX1 $-/+$ mice with clubfoot-like malformation [4]. Second, similar lateral muscle hypoplasia was seen in a patient with $H O X C 13$ deletion [3]. Although replacement of the peroneal muscles with fat is the most striking MRI abnormality in these limbs, decreased muscle mass and increased perimysial fat also are present throughout suggesting a generalized process that is more severe in the lateral leg.

Hypoplasia of lateral muscles manifests clinically as loss of foot-everter function, which is, in our experience, often associated with clubfoot treatment resistance. Others have found the drop toe sign to be a clinical indicator of poor response to traditional clubfoot treatment [28], and we confirmed, in a small number of patients, that this clinical sign also is associated with more severe imaging abnormalities [55]. Vascular abnormalities historically have been evaluated using invasive angiography or intravenous contrast dyes that may cause adverse events [39, 44, 67]; to mitigate this risk, we developed a noninvasive, noncontrast electrocardiography-gated MR angiography method to image the lower extremity vasculature [53]. Using these methods, we identified vascular anomalies in patients with clubfoot and vertical talus, suggesting a shared etiology. Vascular anomalies were identified in four of 10 patients with clubfoot treated nonsurgically [53] (Fig. 4A), three of whom had treatment-resistant clubfoot and muscle hypoplasia on imaging (Fig. 4B). Furthermore, one patient with treatment-resistant clubfoot and a vascular anomaly also had a PITX1 mutation [4]. The spectrum of corresponding muscular and vascular anomalies in patients with clubfoot and PITX1 mutations, and those seen in our PITX1 haploinsufficient clubfoot mice suggest that defects in the PITX1-TBX4-HOX transcriptional pathway give rise to a developmental field defect, in which altered early limb growth results in abnormalities of all derived tissues, including vasculature, muscle, and bone. Furthermore, our data suggest that some morphologic abnormalities, which may result from specific gene mutations, negatively affect clubfoot treatment by making it more difficult to correct or causing recurrence of deformity.

\section{Morphologic Abnormalities Associated With Clubfoot Treatment Resistance}

To more-comprehensively determine whether morphologic abnormalities of the leg are associated with treatment-resistant clubfoot, we performed MRI on 20 patients between 2 and 50 years old with clubfoot [55]. Morphologic abnormalities, consisting of either increased perimysial fat (Fig. 5A), increased intramuscular fat (Fig. 5B), or muscle aplasia/hypoplasia (Fig. 5C), were common in patients with treatment-resistant clubfoot and rarely seen in patients whose clubfoot were easily treated. Intramuscular fat replacement also occurs in human myopathies and spinal cord lesions, some of which can be associated with early limb contractures [15]. The other two patterns, increased perimysial fat, and specific muscle group hypoplasia, have not been reported previously with clubfoot or any other disorder, although lateral muscle group hypoplasia in clubfoot associated with PITX1 mutations was described [4]. Specific muscle group hypoplasia correlates closely with focal neurologic abnormalities, such as the drop toe sign that is present in approximately $5 \%$ of patients with clubfoot [28]. Recognizing these deficits early is necessary so that specific treatments can be planned, including use of electrical stimulation to build up weak, but present, muscles, and avoiding surgical transfer of a tendon whose muscle is atrophic or absent. Future studies are needed to determine whether clinical examination is sufficiently sensitive to detect all clinically actionable abnormalities, and to determine any added benefit of MRI in clinical care. 
Fig. 4A-B In a patient with unilateral right clubfoot, MR images showed (A) decreased muscle volume (arrow) and (B) an absent anterior tibial artery (arrow) in the right leg.
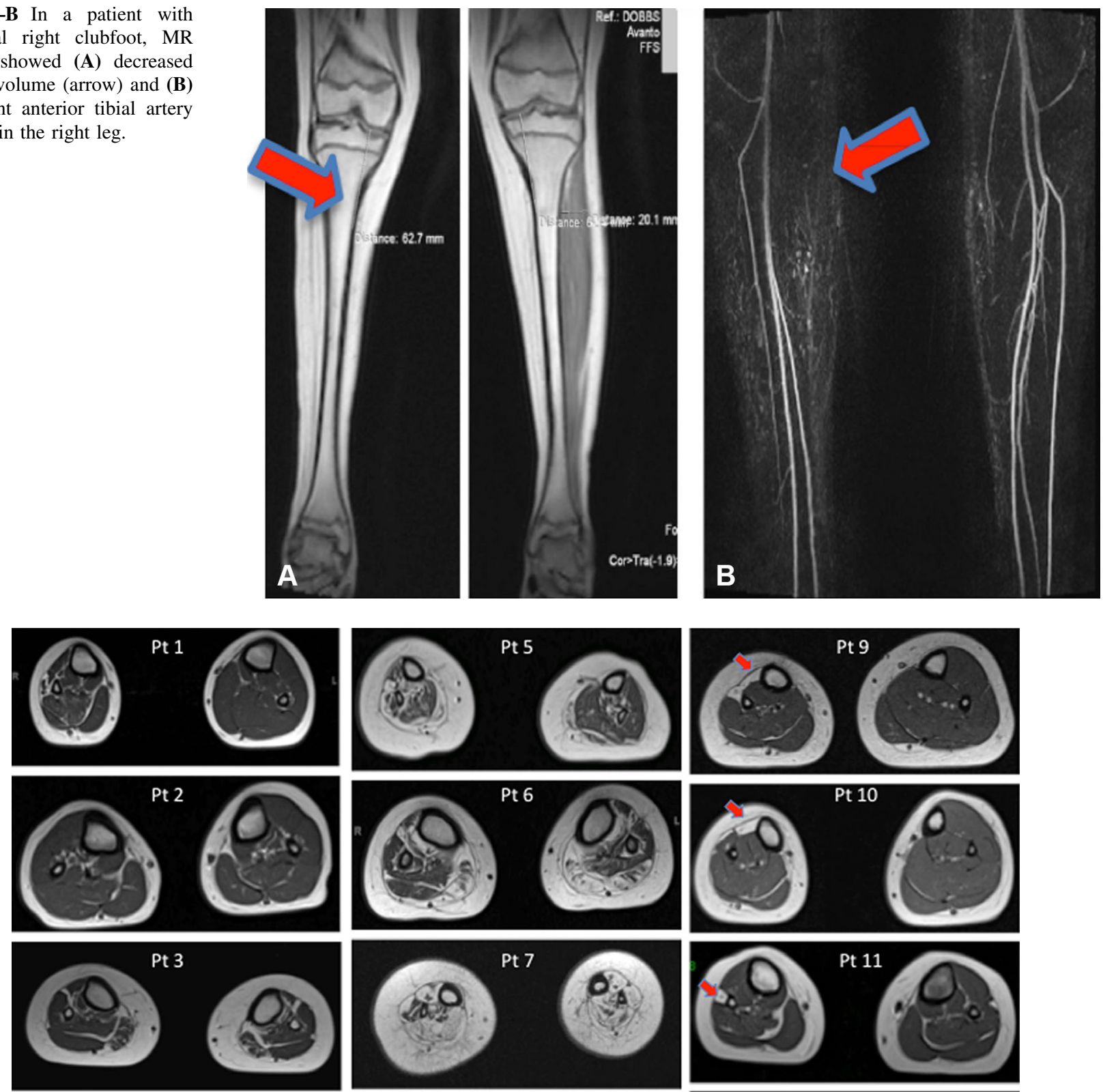

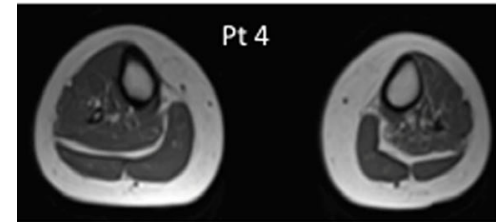

A Perimysial fat

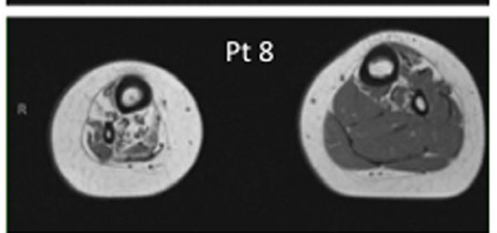

B Intramuscular fat

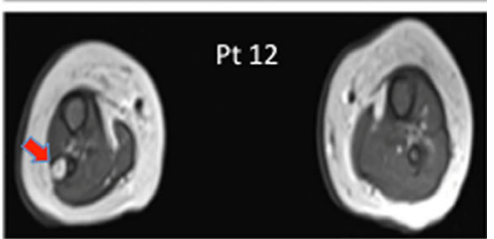

C Muscle aplasia
Fig. 5A-C Morphologic abnormalities identified in treatment-resistant clubfoot can be classified by predominant pathology identified by MRI: (A) increased perimysial fat shown in four individuals with clubfoot, (B) increased intramuscular fat shown in four individuals

Personalized Treatment Methods for Clubfoot and Vertical Talus

Although many patients treated with the Ponseti method have minimal pain or disability, more than $40 \%$ of all with clubfoot, and (C) specific muscle group hypoplasia shown in four individuals with clubfoot. The arrows in Illustration $\mathrm{C}$ indicate unilateral anterior (top two images) and lateral group muscle hypoplasia (lower two images).

patients do not respond to initial treatment or have recurrent malformations develop resulting in additional casting, years of bracing, and/or extensive surgery [14, 22, 38, 71]. As a consequence, patients who underwent surgery often had lifelong foot pain and arthritis develop, and had lower 
quality-of-life scores than patients with congestive heart failure or end-stage kidney disease [11, 19]. Furthermore, many patients with syndromic clubfoot have traditionally been treated with surgery, often with poor outcomes. Development of alternative treatment strategies for treatment-resistant clubfoot therefore is a priority.

We and others successfully extended the Ponseti method of treatment to treat clubfeet associated with arthrogryposis [9], myelomeningocele [34], and with other concomitant limb defects [63]. In addition, we used the Ponseti method to treat older patients with neglected clubfoot (Fig. 6A) resulting in functional anterograde feet (Fig. 6B), patients with complex clubfoot [61], and patients who previously were treated with extensive surgery [7] but had severe relapse [31]. While these patients are more difficult to treat, often undergoing more casting to correct and having a higher risk of recurrence, their outcomes can be excellent and their treatment rewarding.

A firm understanding of principles of the Ponseti method led us to develop a casting technique to successfully correct isolated $[20,21]$ and syndromic congenital vertical talus (Fig. 7A) [1, 12, 69] into anterograde feet with excellent function (Fig. 7B). A close relationship between clubfoot and vertical talus was noted because we had treated a handful of patients with clubfoot on one foot and vertical talus on the other, who had similar, but often opposite, vascular abnormalities on our imaging studies [44]. The Dobbs treatment method relies on a casting method in which some of the applied forces are opposite those used in the Ponseti method to treat clubfoot, and therefore this method may also be referred to as the reverse Ponseti method. The Dobbs treatment method for vertical talus has been reproduced successfully around the world [7, 8, 13, 25-27, 62, 72, 75], with superior results in terms of function and mobility of the foot compared with vertical talus treated with more-extensive surgery [75].

The inability to adequately treat clubfoot may be attributable to our incomplete knowledge of the underlying abnormality. We and others have shown that treatment outcome correlates with the etiology, as patients with syndromic clubfoot, including patients with meningomyelocele and arthrogryposis, have higher rates of relapse resulting in extensive surgery compared with those with isolated clubfoot $[9,34,37]$. A high rate of treatment resistance also has been reported in patients with clubfoot with chromosome $17 \mathrm{q} 23$ microduplications involving TBX4 [2] and PITX1 mutations [36]. However, the majority of patients with clubfoot do not have a specific genetic diagnosis.

Research from our group and others has shown that use of bracing as prescribed is one of the most important predictors of outcome $[22,56]$. Noncompliance may be the result of poorly fitting braces or blistering that occur more commonly with complex clubfoot, but may be related to other factors, including irritability caused by the restrictiveness of the brace, or lack of knowledge about the importance of bracing. After listening to parents in clinic and chatting on internet blogs, we developed a dynamic, articulating clubfoot brace to improve brace comfort and tolerance (Fig. 8) [32]. Many other aspects of brace wear, including the ideal length and timing of bracing, now can be studied with temperature-monitoring devices that can be placed in the brace to quantitatively determine use of bracing.

To understand how to prevent clubfoot recurrence after initial correction, we are leading a randomized multicenter clinical trial to identify optimal length of foot abduction bracing, and to determine the additional clinical and genetic factors that negatively affect treatment outcome. Ponseti and Smoley [60] initially recommended only approximately 2 years of bracing, however, a subsequent study suggested that longer bracing may be more effective [56]. We initiated a prospective randomized trial in which patients with isolated clubfoot receive either 2 or 4 years of foot abduction bracing after successful correction with the Ponseti method. Clinical variables collected as part of the foot abduction brace study (FAB24) include foot length and circumference, calf circumference, and neurologic information such as the ability to dorsiflex and plantar flex
Fig. 6A-B A 19-year-old patient with unilateral neglected clubfoot was treated with the Ponseti method. The patient's clinical images (A) before treatment and (B) 1 year after treatment are shown.
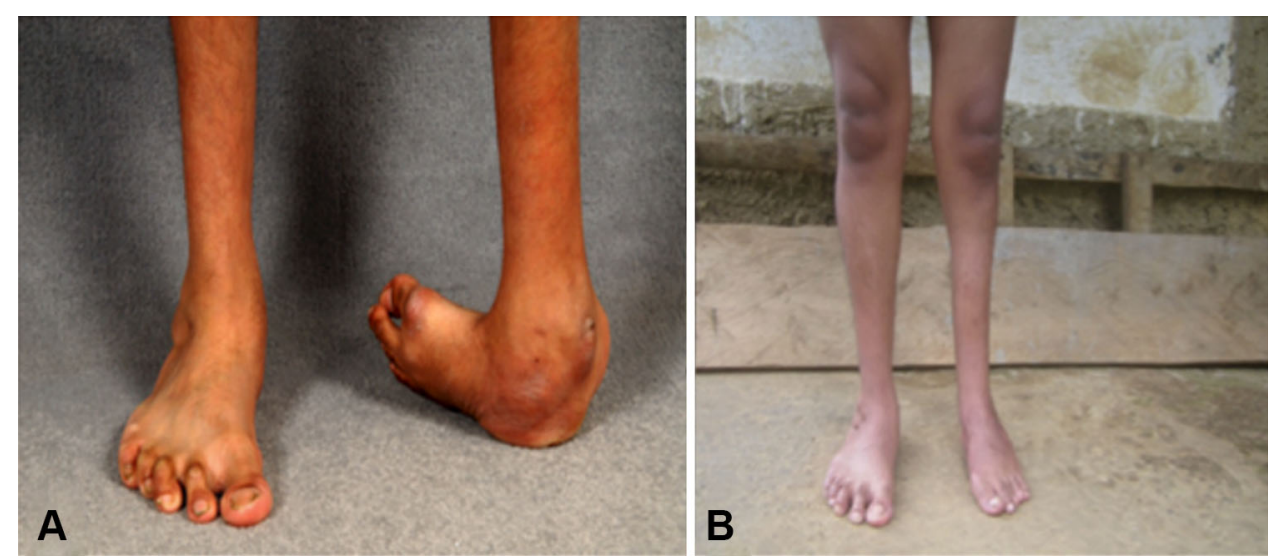
Fig. 7A-B An infant with bilateral vertical talus was treated with the Dobbs method, also called the reverse Ponseti method. The patient's clinical images (A) before treatment and (B) 10 years after treatment are shown.
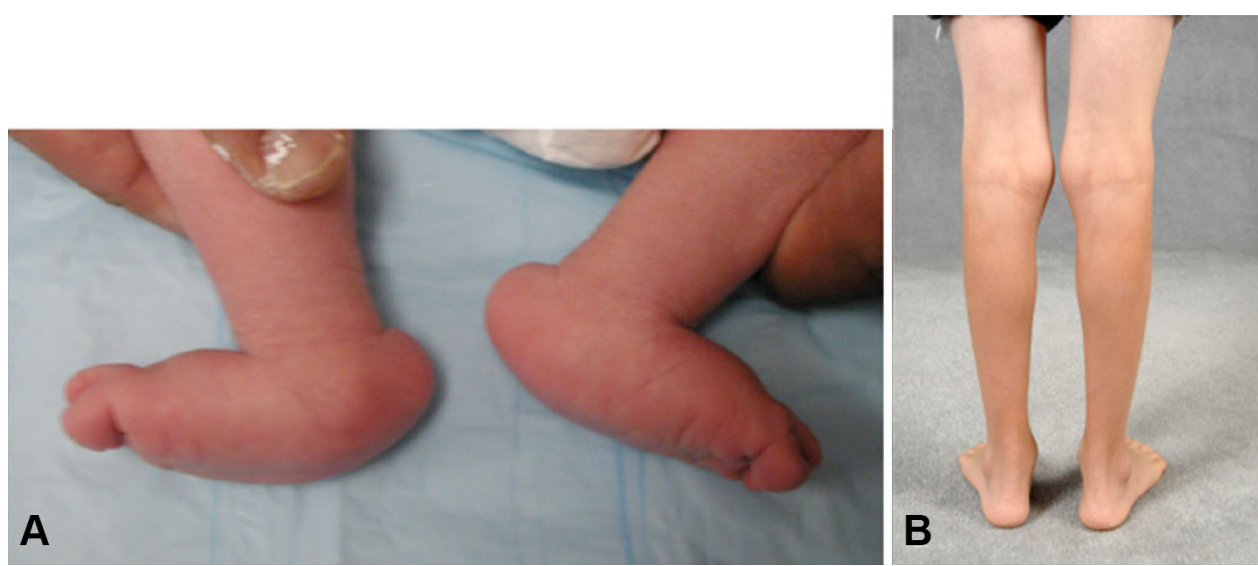

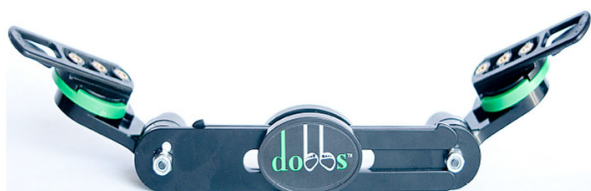

Fig. 8 The Dobbs foot abduction brace has articulating features allowing for leg movement while a patient wears the brace.

the toes and fire the foot everters with stimulation. Our goal is to identify clinical characteristics that the pediatric orthopaedic surgeon can identify at presentation that will help predict response to treatment. Enrollment of 139 patients has been completed at eight participating centers across North America, and the study is expected to be completed in 2020 [17].

The goal of the foot abduction brace study is to allow prescription of individualized treatment protocols to eliminate years of unnecessary bracing in some patients while identifying others who may benefit from earlier tendon transfer surgery or physical therapy intervention focused on everter strengthening. Because not all clubfeet respond to the same treatment, the development of a more-personalized approach is likely the next major advancement in the treatment of clubfoot.

\section{Conclusion}

The ultimate goal of our research is to develop novel treatment methods that are based on an understanding of the underlying biology. Knowledge of the genetic diagnosis and resultant anatomic abnormalities will allow us to develop personalized therapies that minimize the extent of surgery by addressing specific muscular, skeletal, vascular, or neuronal deficits. For example, electrical stimulation of muscle has been described in clubfoot [33], and we are now using it to treat a group of patients with clubfoot and focal muscle hypoplasia. Future improvements in the use of botulinum toxin injections to weaken overactive antagonist muscles in clubfoot also may benefit from optimized muscle selection based on examination findings or imaging $[6,16]$. Furthermore, tendon transfers that are commonly used to correct muscle imbalance in clubfoot $[29,46,75,76]$ would be predicted to fail if the transferred tendon derives from a hypoplastic muscle.

We have been privileged to have been inspired by such a great mentor, Dr. Ponseti, and we hope that our work will inspire scientists and clinicians to develop ever better methods for the treatment of these common pediatric orthopaedic disorders.

Acknowledgments We thank our patients and their families for their continued support and participation in our research studies. Funding was provided by Shriners Hospitals for Children, March of Dimes Foundation, Eunice Kennedy Shriver National Institute of Child Health and Human Development, Orthopaedic Research and Education Foundation, The Discovery Institute of Saint Louis Children's Hospital and Washington University, National Institute of Arthritis and Musculoskeletal and Skin Diseases (Grant No. RO1AR067715-01), and University of Missouri Spinal cord Injury Research Program. Research reported in this publication was supported by the Eunice Kennedy Shriver National Institute of Child Health \& Human Development of the National Institutes of Health under Award Number U54 HD087011 to the Intellectual and Developmental Disabilities Research Center at Washington University. The project described was supported by the National Center for Research Resources and the National Center for Advancing Translational Sciences, National Institutes of Health, through Grant UL1 TR001414. The content is solely the responsibility of the authors and does not necessarily represent the official views of the National Institutes of Health.

\section{References}

1. Alaee F, Boehm S, Dobbs MB. A new approach to the treatment of congenital vertical talus. J Child Orthop. 2007;1:165-174.

2. Alvarado DM, Aferol H, McCall K, Huang JB, Techy M, Buchan J, Cady J, Gonzales PR, Dobbs MB, Gurnett CA. Familial isolated clubfoot is associated with recurrent chromosome 17q23.1q23.2 microduplications containing TBX4. Am J Hum Genet. 2010;87:154-160. 
3. Alvarado DM, Buchan JG, Frick SL, Herzenberg JE, Dobbs MB, Gurnett CA. Copy number analysis of 413 isolated talipes equinovarus patients suggests role for transcriptional regulators of early limb development. Eur J Hum Genet. 2013;21:373380 .

4. Alvarado DM, McCall K, Aferol H, Silva MJ, Garbow JR, Spees WM, Patel T, Siegel M, Dobbs MB, Gurnett CA. Pitx1 haploinsufficiency causes clubfoot in humans and a clubfoot-like phenotype in mice. Hum Mol Genet. 2011;20:3943-3952.

5. Alvarado DM, McCall K, Hecht JT, Dobbs MB, Gurnett CA. Deletions of 5' HOXC genes are associated with lower extremity malformations, including clubfoot and vertical talus. $J$ Med Genet. 2016;53:250-255.

6. Alvarez CM, De Vera MA, Chhina H, Williams L, Durlacher K, Kaga S. The use of botulinum type A toxin in the treatment of idiopathic clubfoot: 5-year follow-up. $J$ Pediatr Orthop. 2009;29:570-575.

7. Aslani H, Sadigi A, Tabrizi A, Bazavar M, Mousavi M. Primary outcomes of the congenital vertical talus correction using the Dobbs method of serial casting and limited surgery. $J$ Child Orthop. 2012;6:307-311.

8. Aydin A, Atmaca H, Muezzinoglu US. Bilateral congenital vertical talus with severe lower extremity external rotational deformity: treated by reverse Ponseti technique. Foot (Edinb). 2012;22:252-254.

9. Boehm S, Limpaphayom N, Alaee F, Sinclair MF, Dobbs MB. Early results of the Ponseti method for the treatment of clubfoot in distal arthrogryposis. J Bone Joint Surg Am. 2008;90:15011507.

10. Bongers EM, Duijf PH, van Beersum SE, Schoots J, Van Kampen A, Burckhardt A, Hamel BC, Losan F, Hoefsloot LH, Yntema HG, Knoers NV, van Bokhoven H. Mutations in the human TBX4 gene cause small patella syndrome. Am J Hum Genet. 2004;74:1239-1248.

11. Brodsky JW. The adult sequelae of treated congenital clubfoot. Foot Ankle Clin. 2010;15:287-296.

12. Chalayon O, Adams A, Dobbs MB. Minimally invasive approach for the treatment of non-isolated congenital vertical talus. $J$ Bone Joint Surg Am. 2012;94:e73.

13. Chan Y, Selvaratnam V, Garg N. A comparison of the Dobbs method for correction of idiopathic and teratological congenital vertical talus. J Child Orthop. 2016;10:93-99.

14. Cooper DM, Dietz FR. Treatment of idiopathic clubfoot: a thirtyyear follow-up note. J Bone Joint Surg Am. 1995;77:1477-1489.

15. Costa AF, Di Primio GA, Schweitzer ME. Magnetic resonance imaging of muscle disease: a pattern-based approach. Muscle Nerve. 2012;46:465-481.

16. Cummings RJ. The effectiveness of botulinum A toxin as an adjunct to the treatment of clubfeet by the Ponseti method: a randomized, double blind, placebo controlled study. J Pediatr Orthop. 2009;29:564-569.

17. Dobbs MB, Frick SL, Mosca VS, Raney E, VanBosse HJ, Lerman JA, Talwalkar VR, Steger-May K, Gurnett CA. Design and descriptive data of the randomized clubfoot foot abduction brace length of treatment study (FAB24). J Pediatr Orthop B. 2017;26:101-107.

18. Dobbs MB, Gurnett CA, Pierce B, Exner GU, Robarge J, Morcuende JA, Cole WG, Templeton PA, Foster B, Bowcock AM. HOXD10 M319K mutation in a family with isolated congenital vertical talus. J Orthop Res. 2006;24:448-453.

19. Dobbs MB, Nunley R, Schoenecker PL. Long-term follow-up of patients with clubfeet treated with extensive soft-tissue release. $J$ Bone Joint Surg Am. 2006;88:986-996.

20. Dobbs MB, Purcell DB, Nunley R, Morcuende JA. Early results of a new method of treatment for idiopathic congenital vertical talus. J Bone Joint Surg Am. 2006;88:1192-1200.
21. Dobbs MB, Purcell DB, Nunley R, Morcuende JA. Early results of a new method of treatment for idiopathic congenital vertical talus: surgical technique. J Bone Joint Surg Am. 2007;89 Suppl 2 Pt.1:111-121.

22. Dobbs MB, Rudzki JR, Purcell DB, Walton T, Porter KR, Gurnett CA. Factors predictive of outcome after use of the Ponseti method for the treatment of idiopathic clubfeet. J Bone Joint Surg Am. 2004;86:22-27.

23. Dobbs MB, Walton T, Gordon JE, Schoenecker PL, Gurnett CA. Flexor digitorum accessorius longus muscle is associated with familial idiopathic clubfoot. J Pediatr Orthop. 2005;25:357-359.

24. Duce SL, D'Alessandro M, Du Y, Jagpal B, Gilbert FJ, Crichton L, Barker S, Collinson JM, Miedzybrodzka Z. 3D MRI analysis of the lower legs of treated idiopathic congenital talipes equinovarus (clubfoot). PLoS One. 2013;8:e54100.

25. Eberhardt O, Fernandez FF, Wirth T. The talar axis-first metatarsal base angle in CVT treatment: a comparison of idiopathic and non-idiopathic cases treated with the Dobbs method. J Child Orthop. 2012;6:491-496.

26. Eberhardt O, Schelling K, Parsch K, Wirth T. [Treatment of congenital clubfoot with the Ponseti method] [in German]. $Z$ Orthop Ihre Grenzgeb. 2006;144:497-501.

27. Eberhardt O, Wirth T, Fernandez FF. [Minimally invasive treatment of congenital foot deformities in infants: new findings and midterm-results] [in German]. Orthopade. 2013;42:1001-1007.

28. Edmonds EW, Frick SL. The drop toe sign: an indicator of neurologic impairment in congenital clubfoot. Clin Orthop Relat Res. 2009;467:1238-1242.

29. Farsetti P, Caterini R, Mancini F, Potenza V, Ippolito E. Anterior tibial tendon transfer in relapsing congenital clubfoot: long-term follow-up study of two series treated with a different protocol. $J$ Pediatr Orthop. 2006;26:83-90.

30. Fried A. Recurrent congenital clubfoot; the role of the M. tibialis posterior in etiology and treatment. J Bone Joint Surg Am. 1959;41:243-252.

31. Garg S, Dobbs MB. Use of the Ponseti method for recurrent clubfoot following posteromedial release. Indian J Orthop. 2008;42:68-72.

32. Garg S, Porter K. Improved bracing compliance in children with clubfeet using a dynamic orthosis. J Child Orthop. 2009;3:271276.

33. Gelfer Y, Durham S, Daly K, Shitrit R, Smorgick Y, Ewins D. The effect of neuromuscular electrical stimulation on congenital talipes equinovarus following correction with the Ponseti method: a pilot study. J Pediatr Orthop B. 2010;19:390-395.

34. Gerlach DJ, Gurnett CA, Limpaphayom N, Alaee F, Zhang Z, Porter K, Kirchhofer M, Smyth MD, Dobbs MB. Early results of the Ponseti method for the treatment of clubfoot associated with myelomeningocele. J Bone Joint Surg Am. 2009;91:1350-1359.

35. Gibson-Brown JJ, Agulnik SI, Chapman DL, Alexiou M, Garvey N, Silver LM, Papaioannou VE. Evidence of a role for T-box genes in the evolution of limb morphogenesis and the specification of forelimb/hindlimb identity. Mech Dev. 1996;56:93-101.

36. Gurnett CA, Alaee F, Kruse LM, Desruisseau DM, Hecht JT, Wise CA, Bowcock AM, Dobbs MB. Asymmetric lower-limb malformations in individuals with homeobox PITX1 gene mutation. Am J Hum Genet. 2008;83:616-622.

37. Gurnett CA, Boehm S, Connolly A, Reimschisel T, Dobbs MB. Impact of congenital talipes equinovarus etiology on treatment outcomes. Dev Med Child Neurol. 2008;50:498-502.

38. Haft GF, Walker CG, Crawford HA. Early clubfoot recurrence after use of the Ponseti method in a New Zealand population. $J$ Bone Joint Surg Am. 2007;89:487-493.

39. Hootnick DR, Levinsohn EM, Crider RJ, Packard DS Jr. Congenital arterial malformations associated with clubfoot: a report of two cases. Clin Orthop Relat Res. 1982;167:160-163. 
40. Ippolito E, De Maio F, Mancini F, Bellini D, Orefice A. Leg muscle atrophy in idiopathic congenital clubfoot: is it primitive or acquired? J Child Orthop. 2009;3:171-178.

41. Ippolito E, Ponseti IV. Congenital club foot in the human fetus: a histological study. J Bone Joint Surg Am. 1980;62:8-22.

42. Irani RN, Sherman MS. The pathological anatomy of idiopathic clubfoot. Clin Orthop Relat Res. 1972;84:14-20.

43. Klopocki E, Kahler C, Foulds N, Shah H, Joseph B, Vogel H, Luttgen S, Bald R, Besoke R, Held K, Mundlos S, Kurth I. Deletions in PITX1 cause a spectrum of lower-limb malformations including mirror-image polydactyly. Eur J Hum Genet. 2012;20:705-708.

44. Kruse L, Gurnett CA, Hootnick D, Dobbs MB. Magnetic resonance angiography in clubfoot and vertical talus: a feasibility study. Clin Orthop Relat Res. 2009;467:1250-1255.

45. Laaveg SJ, Ponseti IV. Long-term results of treatment of congenital club foot. J Bone Joint Surg Am. 1980;62:23-31.

46. Lampasi M, Bettuzzi C, Palmonari M, Donzelli O. Transfer of the tendon of tibialis anterior in relapsed congenital clubfoot: longterm results in 38 feet. J Bone Joint Surg Br. 2010;92:277-283.

47. Lanctot C, Lamolet B, Drouin J. The bicoid-related homeoprotein Ptx1 defines the most anterior domain of the embryo and differentiates posterior from anterior lateral mesoderm. Development. 1997;124:2807-2817.

48. Logan M, Tabin CJ. Role of Pitx1 upstream of Tbx4 in specification of hindlimb identity. Science. 1999;283:1736-1739.

49. Lu W, Bacino CA, Richards BS, Alvarez C, VanderMeer JE, Vella M, Ahituv N, Sikka N, Dietz FR, Blanton SH, Hecht JT. Studies of TBX4 and chromosome 17q23.1q23.2: an uncommon cause of nonsyndromic clubfoot. Am J Med Genet A. 2012;158A:1620-1627.

50. Marcil A, Dumontier E, Chamberland M, Camper SA, Drouin J. Pitx1 and Pitx2 are required for development of hindlimb buds. Development. 2003;130:45-55.

51. Margulies EH, Kardia SL, Innis JW. A comparative molecular analysis of developing mouse forelimbs and hindlimbs using serial analysis of gene expression (SAGE). Genome Res. 2001;11:1686-1698.

52. Menke DB, Guenther C, Kingsley DM. Dual hindlimb control elements in the Tbx4 gene and region-specific control of bone size in vertebrate limbs. Development. 2008;135:2543-2553.

53. Merrill LJ, Gurnett CA, Siegel M, Sonavane S, Dobbs MB. Vascular abnormalities correlate with decreased soft tissue volumes in idiopathic clubfoot. Clin Orthop Relat Res. 2011;469:1442-1449.

54. Miedzybrodzka Z. Congenital talipes equinovarus (clubfoot): a disorder of the foot but not the hand. J Anat. 2003;202:37-42.

55. Moon DK, Gurnett CA, Aferol H, Siegel MJ, Commean PK, Dobbs MB. Soft-tissue abnormalities associated with treatmentresistant and treatment-responsive clubfoot: findings of MRI Analysis. J Bone Joint Surg Am. 2014;96:1249-1256.

56. Morcuende JA, Dolan LA, Dietz FR, Ponseti IV. Radical reduction in the rate of extensive corrective surgery for clubfoot using the Ponseti method. Pediatrics. 2004;113:376-380.

57. Nelson CE, Morgan BA, Burke AC, Laufer E, DiMambro E, Murtaugh LC, Gonzales E, Tessarollo L, Parada LF, Tabin C. Analysis of Hox gene expression in the chick limb bud. Development. 1996;122:1449-1466.

58. Peterson JF, Ghaloul-Gonzalez L, Madan-Khetarpal S, Hartman J, Surti U, Rajkovic A, Yatsenko SA. Familial microduplication of 17q23.1-q23.2 involving TBX4 is associated with congenital clubfoot and reduced penetrance in females. Am J Med Genet A. 2014;164A:364-369.

59. Ponseti IV. Treatment of congenital club foot. J Bone Joint Surg Am. 1992;74:448-454.
60. Ponseti IV, Smoley EN. Congenital clubfoot: the results of treatment. J Bone Joint Surg Am. 1963;45:261-276.

61. Ponseti IV, Zhivkov M, Davis N, Sinclair M, Dobbs MB, Morcuende JA. Treatment of the complex idiopathic clubfoot. Clin Orthop Relat Res. 2006;451:171-176.

62. Rodriguez N, Choung DJ, Dobbs MB. Rigid pediatric pes planovalgus: conservative and surgical treatment options. Clin Podiatr Med Surg. 2010;27:79-92.

63. Shah NR, Limpaphayom N, Dobbs MB. A minimally invasive treatment protocol for the congenital dislocation of the knee. $J$ Pediatr Orthop. 2009;29:720-725.

64. Shapiro MD, Bell MA, Kingsley DM. Parallel genetic origins of pelvic reduction in vertebrates. Proc Natl Acad Sci U $S$ A. 2006;103:13753-13758.

65. Shou S, Scott V, Reed C, Hitzemann R, Stadler HS. Transcriptome analysis of the murine forelimb and hindlimb autopod. Dev Dyn. 2005;234:74-89.

66. Shrimpton AE, Levinsohn EM, Yozawitz JM, Packard DS Jr, Cady RB, Middleton FA, Persico AM, Hootnick DR. A HOX gene mutation in a family with isolated congenital vertical talus and Charcot-Marie-Tooth disease. Am J Hum Genet. 2004;75:9296.

67. Sodre H, Bruschini S, Mestriner LA, Miranda F Jr, Levinsohn EM, Packard DS, Jr., Crider RJ, Jr., Schwartz R, Hootnick DR. Arterial abnormalities in talipes equinovarus as assessed by angiography and the Doppler technique. J Pediatr Orthop. 1990;10:101-104.

68. Spielmann M, Brancati F, Krawitz PM, Robinson PN, Ibrahim DM, Franke M, Hecht J, Lohan S, Dathe K, Nardone AM, Ferrari P, Landi A, Wittler L, Timmermann B, Chan D, Mennen U, Klopocki E, Mundlos S. Homeotic arm-to-leg transformation associated with genomic rearrangements at the PITX1 locus. Am J Hum Genet. 2012;91:629-635.

69. Sweet LA, O’Neill LM, Dobbs MB. Serial casting for neuromuscular flatfoot and vertical talus in an adolescent with hereditary spastic paraplegia. Pediatr Phys Ther. 2014;26:253264.

70. Szeto DP, Ryan AK, O'Connell SM, Rosenfeld MG. P-OTX: a PIT-1-interacting homeodomain factor expressed during anterior pituitary gland development. Proc Natl Acad Sci U S A. 1996;93:7706-7710.

71. Willis RB, Al-Hunaishel M, Guerra L, Kontio K. What proportion of patients need extensive surgery after failure of the Ponseti technique for clubfoot? Clin Orthop Relat Res. 2009;467:12941297.

72. Wright J, Coggings D, Maizen C, Ramachandran M. Reverse Ponseti-type treatment for children with congenital vertical talus: comparison between idiopathic and teratological patients. Bone Joint J. 2014;96:274-278.

73. Wynne-Davies R. Family studies and the cause of congenital club foot: talipes equinovarus, talipes calcaneo-valgus and metatarsus varus. J Bone Joint Surg Br. 1964;46:445-463.

74. Wynne-Davies R. Genetic and environmental factors in the etiology of talipes equinovarus. Clin Orthop Relat Res. 1972;84:913.

75. Yang JS, Dobbs MB. Treatment of congenital vertical talus: comparison of minimally invasive and extensive soft-tissue release procedures at minimum five-year follow-up. J Bone Joint Surg Am. 2015;97:1354-1365.

76. Zhang TX, Haller G, Lin P, Alvarado DM, Hecht JT, Blanton SH, Stephens Richards B, Rice JP, Dobbs MB, Gurnett CA. Genomewide association study identifies new disease loci for isolated clubfoot. J Med Genet. 2014;51:334-339. 